\title{
Erratum to: Is the Shape of the Age-Crime Curve Invariant by Sex? Evidence from a National Sample with Flexible Non-parametric Modeling
}

\section{Siyu Liu}

Published online: 25 May 2014

(C) Springer Science+Business Media New York 2014

\section{Erratum to: J Quant Criminol DOI 10.1007/s10940-014-9225-6}

Unfortunately the correct versions of images for Fig. 2 have not been used in the original publication of the article. Figure 2 should be displayed as follows:

The online version of the original article can be found under doi:10.1007/s10940-014-9225-6.

S. Liu $(\bowtie)$

School of Criminal Justice, University at Albany, 135 Western Ave., Albany, NY 12222, USA

e-mail: sliu@albany.edu 


\section{(A) CRIMINAL BEHAVIOR}

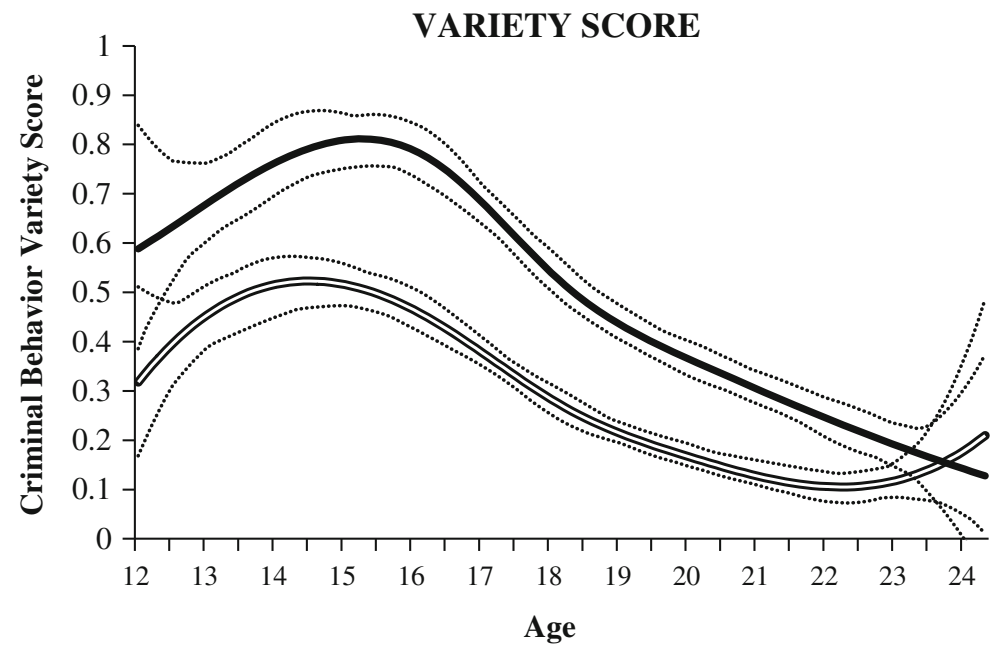

- Male Predicted $\leftrightharpoons$ Female Predicted

(B) FREQUENCY OF ARREST

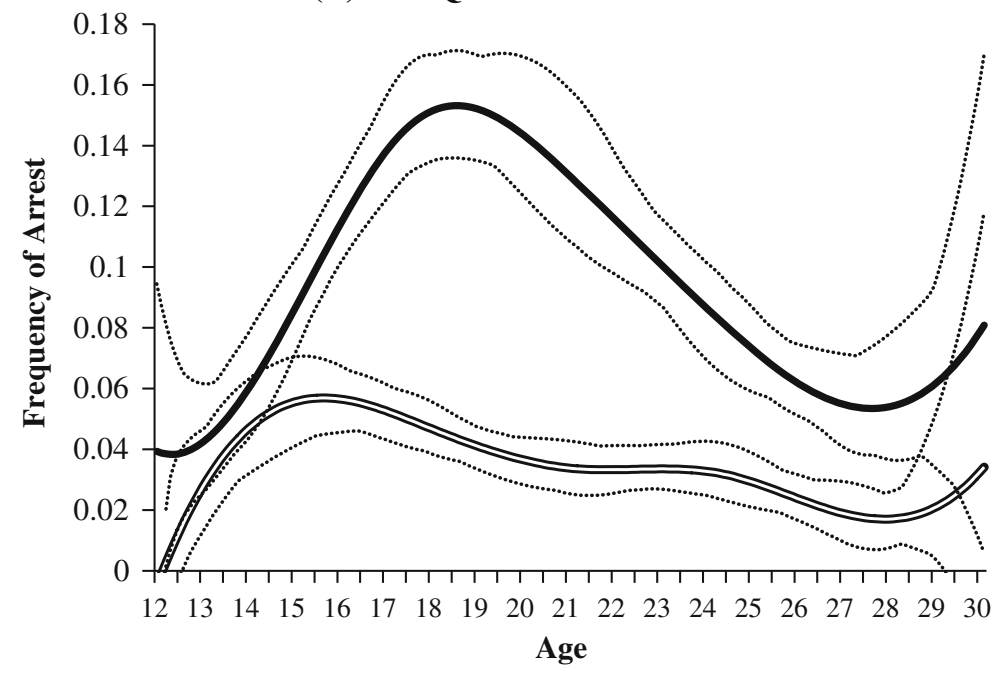

- Male Predicted $\simeq$ Female Predicted

Fig. 2 Age-crime curve by spline regression models. The dotted lines above and below the main curves are intervals of minimum and maximum values. Confidence intervals are not shown here due to their small scale 